Volume 8. No. 7, July 2020

International Journal of Emerging Trends in Engineering Research

Available Online at http://www.warse.org/IJETER/static/pdf/file/ijeter149872020.pdf

https://doi.org/10.30534/ijeter/2020/149872020

\title{
Analysis and Mitigation of Multimodal SSR using Kalman Filter based SSDC in Non-identical Generators
}

\author{
S. Venkateswarlu ${ }^{1}$, M. Janaki ${ }^{2 *}$ \\ ${ }^{1}$ Research Scholar, School of Electrical Engineering, Vellore Institute of Technology, Vellore, India, Email Id: \\ chvreddy237@gmail.com \\ ${ }^{2}$ Associate Professor, School of Electrical Engineering, Vellore Institute of Technology, Vellore, India, Email Id: \\ mjanaki74@gmail.com
}

\begin{abstract}
The multimodal non-identical generators having close frequency modes may complicate the design of Subsynchronous Damping Controller (SSDC). In this paper, we propose a multimodal SSDC using Kalman Filter (KF) to damp Subsynchronous Resonance (SSR). The proposed SSDC is incorporated with Static Synchronous Series Capacitor (SSSC). The system is adapted from the IEEE First Benchmark Model (FBM) with two non-identical generators in parallel. One of the generators has a six-mass mechanical system and other has a four-mass mechanical system. The KF based SSDC is designed to adjust the SSSC injected voltage as to suppress the subsynchronous currents flow to generators. The parameters of KF based SSDC are selected to enrich the torsional modes of both generators. The results show that the peak negative damping viewed at both generators is substantially reduced with proposed KF based SSDC and mitigate SSR.
\end{abstract}

Key words : Static synchronous series capacitor, Non-identical generators, Subsynchronous resonance, Kalman filter, Subsynchronous damping controller.

\section{INTRODUCTION}

The long transmission lines are most used to transmit power from remote resources. Nonetheless, the power loading of a long transmission line is limited by thermal constraint and stability issues. In power systems, the series capacitor compensation is an affordable solution to increase the power transfer capability of the transmission lines. Adversely, the use of series capacitor compensation can cause SSR problem which can lead to extreme interactions between the mechanical system of the turbine-generator and the electrical network. Thereby, the shaft breakage of the turbine-generator occurs after cumulative SSR events. The hybrid series compensation with the incorporation of FACTS devices is made possible to counteract the SSR by using an SSDC at its controller. Also, the use of FACTS devices provides the controllability of power flow through transmission lines, and thereby the system stability can be improved [1]-[4].

In the literature there exist various SSDCs with FACTS devices, which are intended to enrich the stability of the system and mitigate the SSR. The SSSC with Band Pass Filter (BPF) based SSDC in one phase and fixed capacitors in other two phases is used to mitigate subsynchronous oscillations and also damp the power swings [5]. The BPF and Band Stop Filter (BSF) based SSDC for STATCOM is used to extract the desired subsynchronous frequency components and the BSF is used to reject the other frequency components [6]. In [7[-[9], the authors proposed Low Pass Filter (LPF) based SSDC to mitigate SSR. The LPF based SSDC is designed for Single Machine connected to Infinite Bus (SMIB) and it is used to extract the fundamental and subsynchronous components from the generator terminal voltage. In [10], the authors proposed BPF based SSDC to suppress the subsynchronous currents following through the generator armature terminal. The Kalman Filter (KF) based SSDC is a highly frequency selective [11].

Recently, the researchers proposed SSDCs for multi-machine system to enhance the torsional damping and to mitigate the multimodal SSR. In [12[, [13], the authors reported Generator Terminal Subsynchronous Damping Controller (GTSDC) for multi-machine system using BPFs. The BPFs are used to extract the torsional mode frequencies from the speed deviations of the generator. The disadvantage of GTSDC is could not maintain system stability. The combined scheme of Supplementary Excitation Damping Controller (SEDC) and GTSDC is proposed to mitigate SSR and enhance the system stability [14], [15]. In [16], the authors proposed family of Subsynchronous Dampers (SSDs) for multi-machine system using BPFs to damp the multimodal SSR. The Newton-Raphson (N-R) and Automatic Differentiation methods are utilized to explore the effect of TCSC on power flow is reported in [17].

It is noted that the design of multimodal SSDC in multi-machine system is more complicated due to the widespread close natural frequencies of mechanical system. 
S. Venkateswarlu et al., International Journal of Emerging Trends in Engineering Research, 8(7), July 2020, 3834 - 3839

In this paper, we proposed a KF based SSDC to enrich all the critical torsional modes of both generators and to mitigate the multimodal SSR. The analysis of SSR is done on the modified IEEE FBM with SSSC and KF based SSDC. The KF based SSDC is designed to reduce the negative damping torque at the torsional mode frequencies. The output of KF based SSDC is used to adjust the SSSC injected voltage as to diminish the subsynchronous frequency currents in the line. The results show that the peak negative damping viewed at both generators is considerably reduced with proposed KF based SSDC and mitigate the multimodal SSR.

The other sections are organized as: The Section II depicts the system description with SSSC type-1 controller and the initial operating points. The design of KF based SSDC is described in Section III. The results are illustrated in Section IV. At last, the conclusions are presented in Section V.

\section{DESCRIPTION OF SYSTEM AND MODELING}

This section presents a brief overview about the system diagram, Type- 1 controller of SSSC, and operating points at which the analysis is performed.

\subsection{System diagram and methods of SSR analysis}
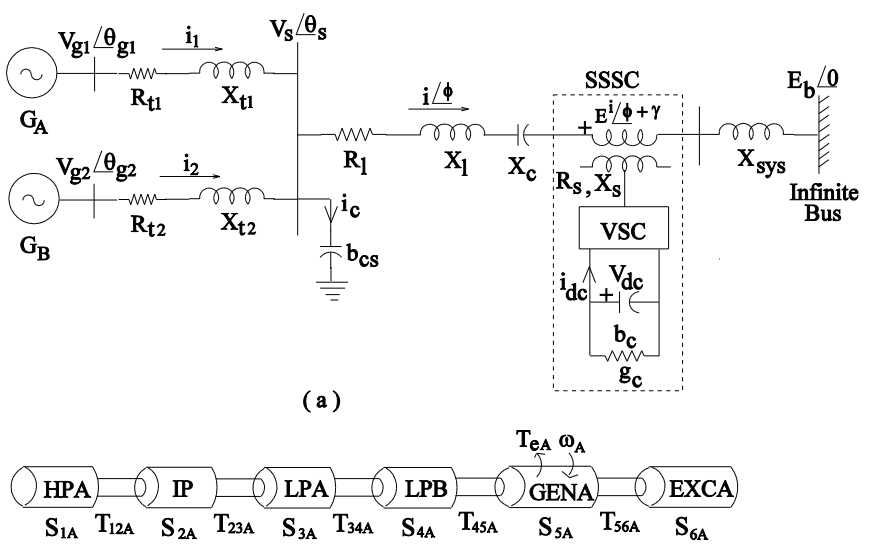

(b)

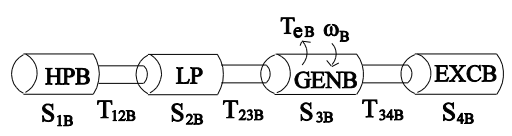

(c)

Figure 1: (a) Multi-machine system with SSSC (b) Six-mass mechanical system of generator-A (c) Four-mass mechanical system of generator-B

The pictorial representation of multi-machine system is shown in Figure 1, which is the modified IEEE FBM with the inclusion of four-mass turbine-generator and SSSC.

The study system consists of two non-identical turbine generators with a rating of 892.4 MVA and 600 MVA on the base of $892.4 \mathrm{MVA}, 60 \mathrm{~Hz}$. The shaft system of generator-A consists of six-masses namely: HPA, IP, LPA, LPB, GENA and EXCA whose torsional mode frequencies are $15.72 \mathrm{~Hz}$, $20.22 \mathrm{~Hz}, 25.56 \mathrm{~Hz}, 32.30 \mathrm{~Hz}$ and $47.48 \mathrm{~Hz}$. Similarly, the shaft system of generator-B consists of four-masses namely:
HPB, LP, GENB and EXCB whose torsional mode frequencies are $24.65 \mathrm{~Hz}, 32.39 \mathrm{~Hz}$ and $51.10 \mathrm{~Hz}$.

The magnitude of the SSSC converter output voltage is

$\left|E^{i}\right|=M_{k} V_{d c}$

Accordingly, the D-Q components of SSSC converter output voltage are given by

$E_{D}^{i}=M_{k} V_{d c} \sin (\phi+\gamma)$.

$E_{Q}^{i}=M_{k} V_{d c} \cos (\phi+\gamma)$.

where $M_{k}$ is the modulation index and $V_{d c}$ is the dc voltage capacitor.

The real and reactive voltages of SSSC are obtained from the DQ quantities as

$$
\begin{aligned}
& E_{P}=E_{D}^{i} \sin (\phi)+E_{Q}^{i} \cos (\phi) \\
& E_{R}=E_{D}^{i} \cos (\phi)-E_{Q}^{i} \sin (\phi)
\end{aligned}
$$

Figure 2 shows the type- 1 controller for SSSC [10], [18]. In Figure 2, the phase angle $\gamma$ and dead angle $\beta_{\text {se }}$ are calculated using the reference values $\mathrm{E}_{\mathrm{P}(\mathrm{se})(\mathrm{ref})}$ and $\mathrm{E}_{\mathrm{R}(\mathrm{se})(\mathrm{ref})}$ as

$$
\begin{aligned}
& \gamma=\tan ^{-1}\left[\frac{E_{R(s e)(r e f)}}{E_{P(s e)(r e f)}}\right] \\
& \beta_{s e}=\cos ^{-1}\left[\frac{\sqrt{E_{P(s e)(r e f)}^{2}+E_{R(s e)(r e f)}^{2}}}{P \rho V_{d c}}\right]
\end{aligned}
$$

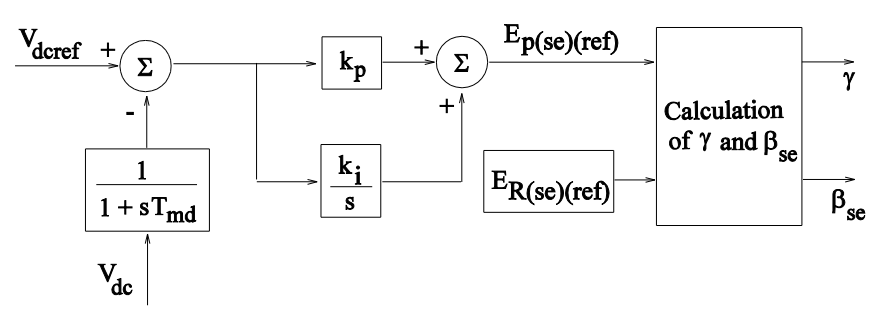

Figure 2: Type-1 controller of SSSC [2], [10]

The differential and algebraic equations of the combined system are used to develop the liner (DQ) model in MATLAB-Simulink. The 2.2 model of two generators are developed for eigenvalue analysis and transient simulation [1]. Whereas, the two non-identical turbine-generators are represented as classical models in damping torque estimation. We perform damping torque, eigenvalue analysis and transient simulation to analyze SSR and to validate the performance of the KF based SSDC connected to SSSC.

\subsection{Initial and operating points}

The initial operating points and assumptions which are used in the analysis are given below.

(1) The output power of generator-A and generator-B is set to 0.65 p.u and 0.5 p.u respectively.

(2) The mechanical power input of the generators $G_{A}$ and $G_{B}$ is assumed to be constant. 
S. Venkateswarlu et al., International Journal of Emerging Trends in Engineering Research, 8(7), July 2020, 3834 - 3839

(3) The hybrid series compensation is provided with $\mathrm{Xc}=$ 0.35 p.u. and Xsssc $=-0.2$ p.u.

\section{SCHEME OF KALMAN FILTER BASED SSDC}

The proposed multimodal SSDC consists of KF and gains $\left(k_{1} t o k_{14}\right)$ as to reduce the peak negative damping and to enrich all critical torsional modes. The pictorial representation of KF based SSDC is shown in Figure 3. The $\mathrm{KF}$ is used to extricate the components pertaining to the subsynchronous frequency from the line to obtain subsynchronous voltages in DQ.

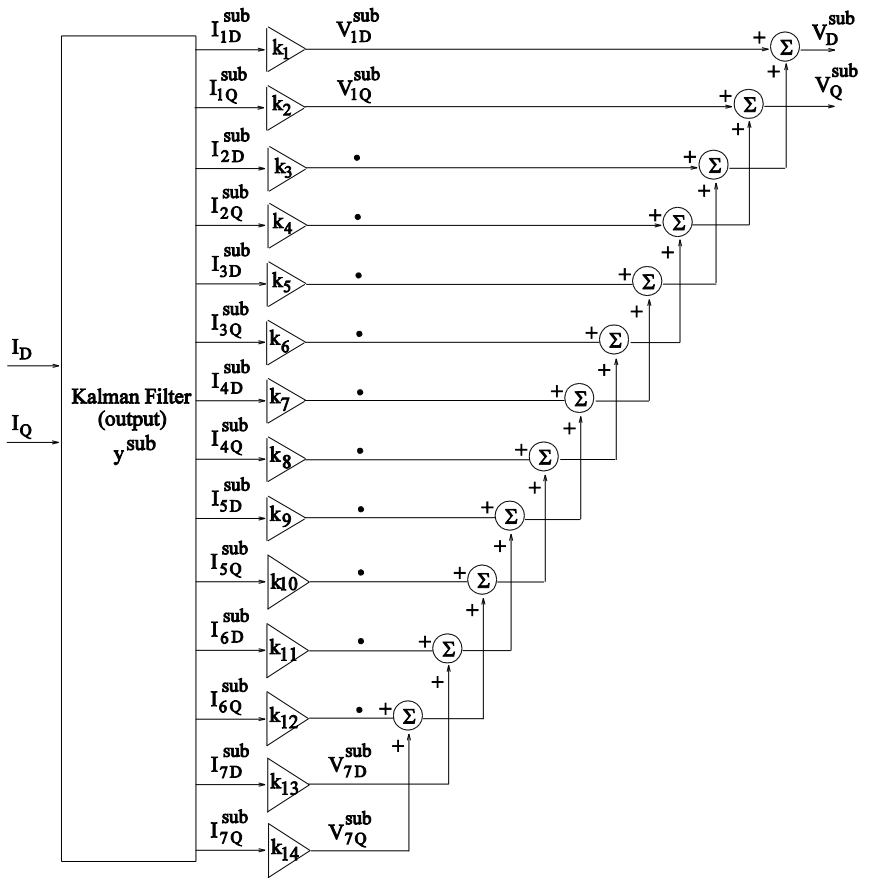

Figure 3: Pictorial representation of proposed KF based SSDC

The output of proposed KF based SSDC is converted to in-phase and quadrature components (real voltage $\mathrm{V}_{\mathrm{psub}}$ and reactive voltage $\mathrm{V}_{\text {Rsub }}$ ) and added to type-1 controller of SSSC is shown in Figure 4. The SSSC can inject the reactive voltage in series with the line to suppress the subsynchronous currents following through the generator armature terminal.

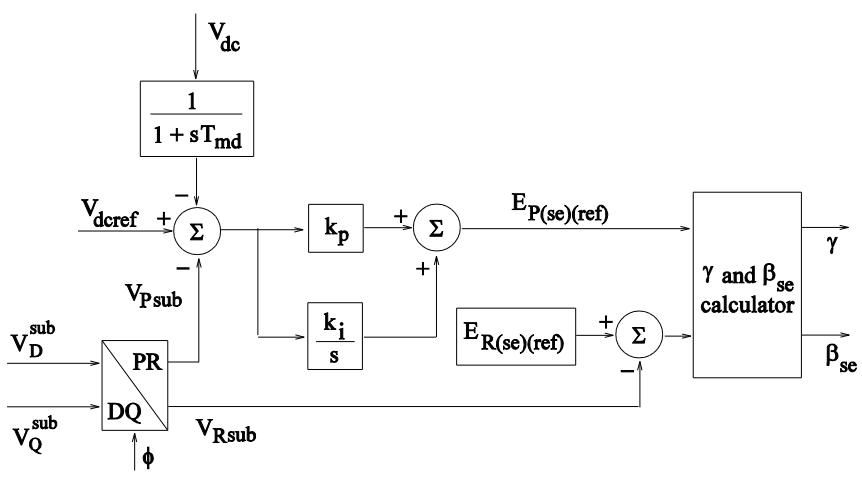

Figure 4: Type-1 controller for SSSC with estimated subsynchronous components from proposed KF based SSDC

\section{RESULTS AND DISCUSSION}

This section presents the analysis of SSR without and with proposed KF based SSDC in the system shown in Figure 1.

\subsection{Damping torque analysis}

In this technique, the two non-identical generators are represented as classical model. The dynamics pertaining to the mechanical system is neglected. The electrical damping torque is calculated from the internal bus of the generators $\mathrm{G}_{\mathrm{A}}$ and $G_{B}$ to infinite bus. The damping torque of the generators $\mathrm{G}_{\mathrm{A}}$ and $\mathrm{G}_{\mathrm{B}}$ for $\mathrm{X}_{\mathrm{C}}=0.35 \mathrm{p}$.u and $\mathrm{X}_{\mathrm{SSSC}}=-0.2 \mathrm{p}$.u without and with proposed KF based SSDC is shown in Figure 5.
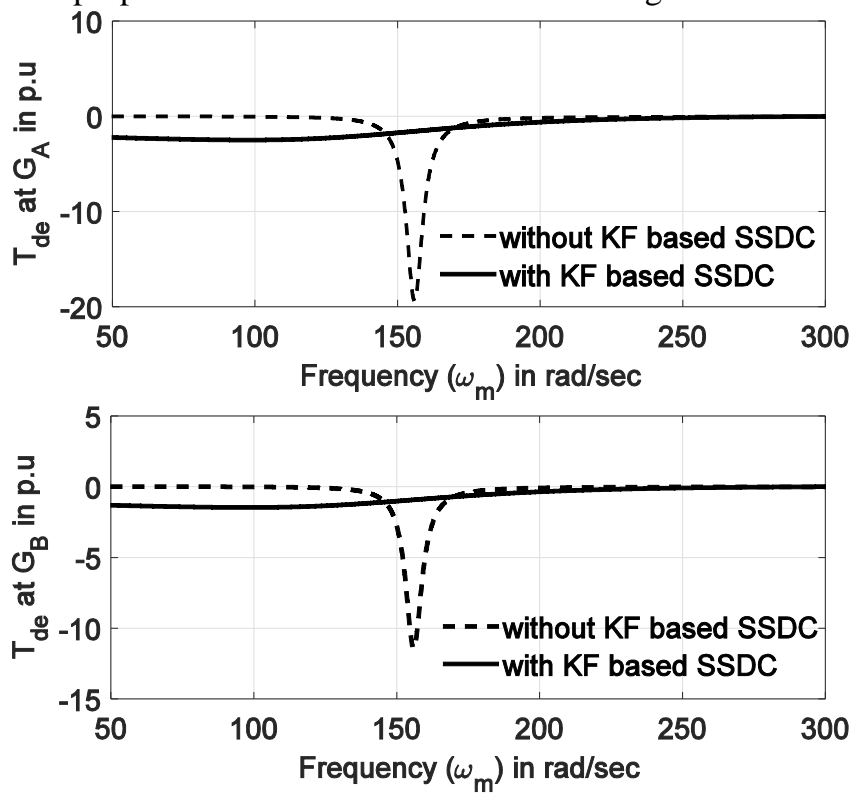

Figure 5: Damping torque of the generators $G_{A}$ and $G_{B}$ without and with proposed KF based SSDC on SSSC for $\mathrm{X}_{\mathrm{C}}=0.35$ p.u and Xsssc $=-0.2$ p.u.

From Figure 5, we observe that without KF based SSDC the peak negative damping occurs at about $155 \mathrm{rad} / \mathrm{sec}$. Hence, the corresponding torsional modes are expected to be unstable. On the other hand, the peak negative damping is noticeably reduced with the proposed KF based SSDC in the entire range of critical torsional modes from 0 to $300 \mathrm{rad} / \mathrm{sec}$.

\subsection{Eigenvalue analysis}

We perform eigenvalue analysis with the detailed synchronous generator 2.2 model. The eigenvalues of the system without and with proposed KF based SSDC on SSSC are tabulated in Table 1 and Table 2 respectively.

We estimated the participation of shaft torque and speed deviation in the torsional modes of two generators $\left(\mathrm{G}_{\mathrm{A}}\right.$ and $\mathrm{G}_{\mathrm{B}}$ ) with $\mathrm{KF}$ based SSDC. Table 3 shows the participation factors of various states of two generators. The participation factor is used to identify the mode belonging to the generators with close frequency modes. The highest participation of state variables are marked in bold. Also, the identified modes are shown in the last row of Table 3 . 
S. Venkateswarlu et al., International Journal of Emerging Trends in Engineering Research, 8(7), July 2020, 3834 - 3839

From the Table 1, we observe that, without KF based SSDC the frequency of $\mathrm{NM}_{\text {Sub }}$ (subsynchronous network mode) is close to frequency of $\mathrm{TM}_{1 \mathrm{G}_{\mathrm{B}}}$ (torsional mode- 1 of generator $\mathrm{G}_{\mathrm{B}}$ ). Hence, the torsional mode- 1 of generator $\mathrm{G}_{\mathrm{B}}$ is unstable.

On the other hand, all the eigenvalues having negative real parts with proposed KF based SSDC as shown in Table 2. It indicates that the system is stable. Also, the damping of all the critical torsional modes are improved with proposed KF based SSDC as compared to without KF based SSDC.

Table 1: Eigenvalues of the system without KF based SSDC on SSSC

\begin{tabular}{|l|c|}
\hline \multirow{2}{*}{ Mode } & SSSC without KF based SSDC \\
\cline { 2 - 3 } & $\mathrm{X}_{\mathrm{c}}=0.35 \mathrm{p} . \mathrm{u}$ and $\mathrm{X}_{\mathrm{sssc}}=-0.2 \mathrm{p} . \mathrm{u}$ \\
\hline $\mathrm{TM}_{0 \mathrm{G}_{\mathrm{A}}}$ & $-0.48223 \pm j 5.19010$ \\
\hline $\mathrm{TM}_{1 \mathrm{G}_{\mathrm{A}}}$ & $-0.24581 \pm j 99.2490$ \\
\hline $\mathrm{TM}_{2 \mathrm{G}_{\mathrm{A}}}$ & $-0.07405 \pm j 127.040$ \\
\hline $\mathrm{TM}_{3 \mathrm{G}_{\mathrm{A}}}$ & $-0.60776 \pm j 160.450$ \\
\hline $\mathrm{TM}_{4 \mathrm{G}_{\mathrm{A}}}$ & $-0.36285 \pm j 202.970$ \\
\hline $\mathrm{TM}_{5 \mathrm{G}_{\mathrm{A}}}$ & $-1.85040 \pm j 298.170$ \\
\hline $\mathrm{TM}_{0 \mathrm{G}_{\mathrm{B}}}$ & $-8.59720 \pm j 8.61320$ \\
\hline $\mathrm{TM}_{1 \mathrm{G}_{\mathrm{B}}}$ & $0.57681 \pm j 155.020$ \\
\hline $\mathrm{TM}_{2 \mathrm{G}_{\mathrm{B}}}$ & $-0.04421 \pm j 203.460$ \\
\hline $\mathrm{TM}_{3 \mathrm{G}_{\mathrm{B}}}$ & $-0.03364 \pm j 321.180$ \\
\hline $\mathrm{NM}_{\mathrm{Sub}}$ & $-3.30550 \pm j 155.130$ \\
\hline $\mathrm{NM}_{\mathrm{Sup}}$ & $-3.05380 \pm j 565.910$ \\
\hline
\end{tabular}

Table 2: Eigenvalues of the system with proposed KF based SSDC on SSSC

\begin{tabular}{|l|c|}
\hline \multirow{2}{*}{ Mode } & SSSC with KF based SSDC \\
\cline { 2 - 3 } & $\mathrm{X}_{\mathrm{c}}=0.35 \mathrm{p} . \mathrm{u}$ and $\mathrm{X}_{\mathrm{sssc}}=-0.2 \mathrm{p} . \mathrm{u}$ \\
\hline $\mathrm{TM}_{0 \mathrm{G}_{\mathrm{A}}}$ & $-0.75461 \pm j 3.71330$ \\
\hline $\mathrm{TM}_{1 \mathrm{G}_{\mathrm{A}}}$ & $-0.26895 \pm j 99.1140$ \\
\hline $\mathrm{TM}_{2 \mathrm{G}_{\mathrm{A}}}$ & $-0.07630 \pm j 127.030$ \\
\hline $\mathrm{TM}_{3 \mathrm{G}_{\mathrm{A}}}$ & $-0.64952 \pm j 160.630$ \\
\hline $\mathrm{TM}_{4 \mathrm{G}_{\mathrm{A}}}$ & $-0.36200 \pm j 203.000$ \\
\hline $\mathrm{TM}_{5 \mathrm{G}_{\mathrm{A}}}$ & $-1.85040 \pm j 298.170$ \\
\hline $\mathrm{TM}_{0 \mathrm{~GB}_{\mathrm{B}}}$ & $-9.12640 \pm j 10.2290$ \\
\hline $\mathrm{TM}_{1 \mathrm{~GB}_{\mathrm{B}}}$ & $-0.05909 \pm j 155.110$ \\
\hline $\mathrm{TM}_{2 \mathrm{~GB}_{\mathrm{B}}}$ & $-0.04324 \pm j 203.460$ \\
\hline $\mathrm{TM}_{3 \mathrm{~GB}_{\mathrm{B}}}$ & $-0.03368 \pm j 321.180$ \\
\hline $\mathrm{NM}_{\mathrm{Sub}}$ & $-77.6170 \pm j 129.670$ \\
\hline $\mathrm{NM}_{\mathrm{Sup}}$ & $-53.1320 \pm j 538.590$ \\
\hline
\end{tabular}

\subsection{Transient simulation}

The transient analysis is performed for large disturbances (of $10 \%$ lessening in mechanical power) with non-linear models. The step response of two generators $G_{A}$ and $G_{B}$ without KF based SSDC for the compensation $\mathrm{X}_{\mathrm{c}}=0.35 \mathrm{p}$. $\mathrm{u}$ is shown in Figure 6 and Figure 7 respectively.
From Figure 6 and Figure 7, we observe that, the magnitude of the oscillatory response of generator $G_{B}$ rises faster than generator $\mathrm{G}_{\mathrm{A}}$. It indicates that, with $10 \%$ lessening in mechanical power, the system is unstable.
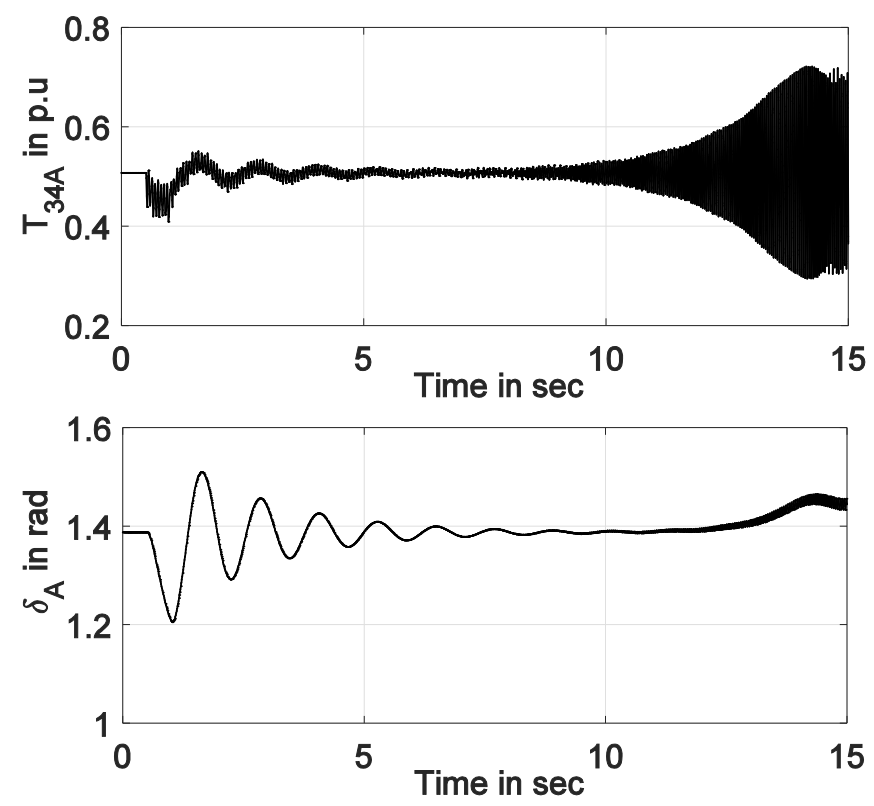

Figure 6: Sectional torque and rotor angle of generator $\mathrm{G}_{A}$ without $\mathrm{KF}$ based SSDC for the compensation Xc $=0.35$ p.u.
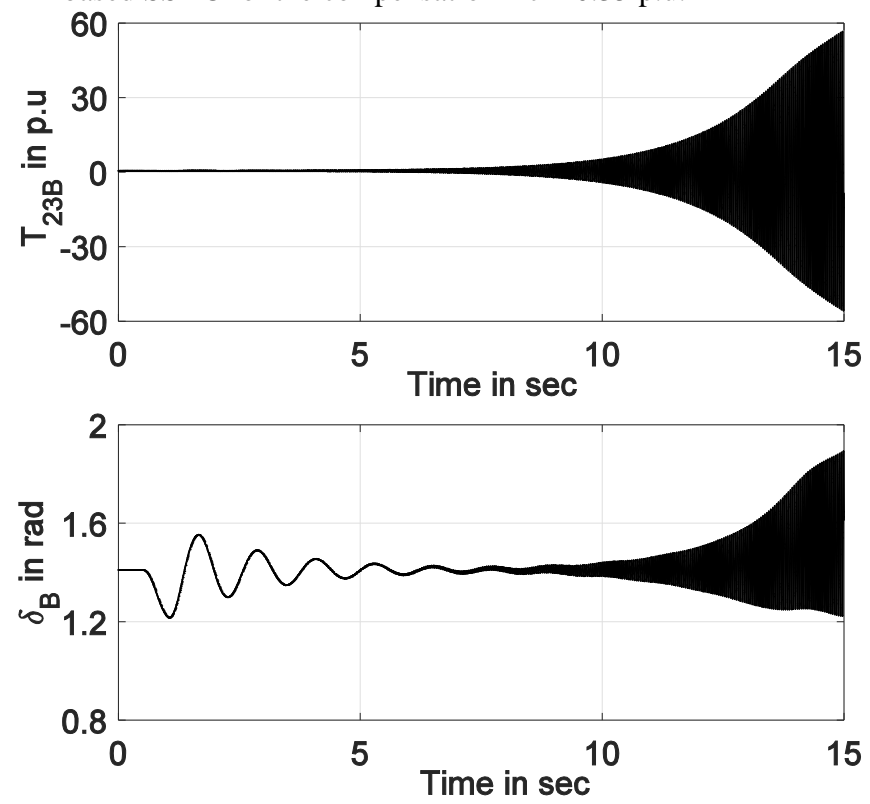

Figure 7: Sectional torque and rotor angle of generator $\mathrm{G}_{\mathrm{B}}$ without $\mathrm{KF}$ based SSDC for the compensation $\mathrm{Xc}=0.35$ p.u.

Similarly, the step response of two generators $G_{A}$ and $G_{B}$ with proposed KF based SSDC for the compensation $\mathrm{Xc}=0.35 \mathrm{p} . \mathrm{u}$ is obtained. We observe that, initially the magnitude of the oscillatory response of both generators $G_{A}$ and $G_{B}$ rises until $t$ $=4 \mathrm{sec}$ as shown in Figure 8 and Figure 9,. When the proposed KF based SSDC is activated at $\mathrm{t}=4 \mathrm{sec}$ the oscillatory response dies out along time. It indicates that system is stable. 
S. Venkateswarlu et al., International Journal of Emerging Trends in Engineering Research, 8(7), July 2020, 3834 - 3839

Table 3: Participation of shaft torque and speed deviation in the torsional modes of generators $\mathrm{G}_{\mathrm{A}}$ and $\mathrm{G}_{\mathrm{B}}$ with $\mathrm{KF}$ based SSDC

\begin{tabular}{|c|c|c|c|c|c|c|c|c|}
\hline \multicolumn{9}{|c|}{ SSSC with KF based SSDC $(\mathrm{Xc}=0.35 \mathrm{p} . \mathrm{u}$ and $\mathrm{Xsssc}=-0.2 \mathrm{p} . \mathrm{u})$} \\
\hline \multirow{3}{*}{$\begin{array}{c}\text { State } \\
\text { variables }\end{array}$} & \multicolumn{8}{|c|}{ Eigenvalues } \\
\hline & $\begin{array}{c}-0.26895 \\
\pm j\end{array}$ & $\begin{array}{c}-0.07630 \\
\pm j\end{array}$ & $\begin{array}{c}-0.64952 \\
\pm j\end{array}$ & $\begin{array}{c}-0.36200 \\
\pm j\end{array}$ & $\begin{array}{c}-1.85040 \\
\pm j\end{array}$ & $\begin{array}{c}-0.05909 \\
\pm j\end{array}$ & $\begin{array}{c}-0.04324 \\
\pm j\end{array}$ & $\begin{array}{c}-0.03368 \\
\pm j\end{array}$ \\
\hline & 99.1140 & 127.030 & 160.630 & 203.000 & 298.170 & 155.110 & 203.460 & 321.180 \\
\hline $\mathrm{G}_{\mathrm{A}}$ & \multicolumn{8}{|c|}{ Participation factors of generator $\mathrm{G}_{\mathrm{A}}$} \\
\hline $\mathrm{T}_{12 \mathrm{~A}}$ & $1.87 \mathrm{e}^{-02}$ & $6.13 \mathrm{e}^{-03}$ & $1.60 \mathrm{e}^{-01}$ & $2.37 \mathrm{e}^{-02}$ & $2.91 \mathrm{e}^{-01}$ & $1.93 \mathrm{e}^{-04}$ & $4.79 \mathrm{e}^{-04}$ & $1.65 \mathrm{e}^{-11}$ \\
\hline $\mathrm{T}_{23 \mathrm{~A}}$ & $5.26 \mathrm{e}^{-02}$ & $1.33 \mathrm{e}^{-02}$ & $2.18 \mathrm{e}^{-01}$ & $1.09 \mathrm{e}^{-02}$ & $2.04 \mathrm{e}^{-01}$ & $2.90 \mathrm{e}^{-04}$ & $2.17 \mathrm{e}^{-04}$ & $2.76 \mathrm{e}^{-11}$ \\
\hline $\mathrm{T}_{34 \mathrm{~A}}$ & $2.75 \mathrm{e}^{-01}$ & $2.39 \mathrm{e}^{-02}$ & $1.88 \mathrm{e}^{-02}$ & $1.76 \mathrm{e}^{-01}$ & $4.44 \mathrm{e}^{-03}$ & $6.12 \mathrm{e}^{-07}$ & $3.61 \mathrm{e}^{-03}$ & $2.63 \mathrm{e}^{-10}$ \\
\hline $\mathrm{T}_{45 \mathrm{~A}}$ & $1.21 \mathrm{e}^{-01}$ & $5.67 \mathrm{e}^{-05}$ & $9.18 \mathrm{e}^{-02}$ & $2.81 \mathrm{e}^{-01}$ & $2.19 \mathrm{e}^{-04}$ & $1.53 \mathrm{e}^{-04}$ & $5.92 \mathrm{e}^{-03}$ & $9.44 \mathrm{e}^{-09}$ \\
\hline $\mathrm{T}_{56 \mathrm{~A}}$ & $2.98 \mathrm{e}^{-02}$ & $4.56 \mathrm{e}^{-01}$ & $9.53 \mathrm{e}^{-03}$ & $4.28 \mathrm{e}^{-03}$ & $3.92 \mathrm{e}^{-07}$ & $6.16 \mathrm{e}^{-06}$ & $9.25 \mathrm{e}^{-05}$ & $3.61 \mathrm{e}^{-10}$ \\
\hline $\mathrm{S}_{1 \mathrm{~A}}$ & $7.47 \mathrm{e}^{-02}$ & $1.49 \mathrm{e}^{-02}$ & $2.43 \mathrm{e}^{-01}$ & $2.25 \mathrm{e}^{-02}$ & $1.28 \mathrm{e}^{-01}$ & $3.15 \mathrm{e}^{-04}$ & $4.53 \mathrm{e}^{-04}$ & $6.28 \mathrm{e}^{-12}$ \\
\hline $\mathrm{S}_{2 \mathrm{~A}}$ & $7.02 \mathrm{e}^{-02}$ & $8.62 \mathrm{e}^{-03}$ & $4.74 \mathrm{e}^{-02}$ & $1.06 \mathrm{e}^{-04}$ & $3.46 \mathrm{e}^{-01}$ & $7.85 \mathrm{e}^{-05}$ & $2.59 \mathrm{e}^{-06}$ & $2.81 \mathrm{e}^{-11}$ \\
\hline $\mathrm{S}_{3 \mathrm{~A}}$ & $1.32 \mathrm{e}^{-01}$ & $2.56 \mathrm{e}^{-03}$ & $1.20 \mathrm{e}^{-01}$ & $7.08 \mathrm{e}^{-02}$ & $2.45 \mathrm{e}^{-02}$ & $8.73 \mathrm{e}^{-05}$ & $1.43 \mathrm{e}^{-03}$ & $4.65 \mathrm{e}^{-11}$ \\
\hline $\mathrm{S}_{4 \mathrm{~A}}$ & $1.57 \mathrm{e}^{-02}$ & $1.83 \mathrm{e}^{-02}$ & $2.01 \mathrm{e}^{-02}$ & $2.90 \mathrm{e}^{-01}$ & $8.78 \mathrm{e}^{-04}$ & $1.01 \mathrm{e}^{-04}$ & $6.02 \mathrm{e}^{-03}$ & $1.81 \mathrm{e}^{-09}$ \\
\hline $\mathrm{S}_{5 \mathrm{~A}}$ & $1.62 \mathrm{e}^{-01}$ & $1.60 \mathrm{e}^{-02}$ & $6.35 \mathrm{e}^{-02}$ & $1.12 \mathrm{e}^{-01}$ & $3.88 \mathrm{e}^{-05}$ & $3.03 \mathrm{e}^{-05}$ & $2.44 \mathrm{e}^{-03}$ & $4.39 \mathrm{e}^{-08}$ \\
\hline$S_{6 A}$ & $4.71 \mathrm{e}^{-02}$ & $4.40 \mathrm{e}^{-01}$ & $5.74 \mathrm{e}^{-03}$ & $1.61 \mathrm{e}^{-03}$ & $6.86 \mathrm{e}^{-08}$ & $3.98 \mathrm{e}^{-06}$ & $3.47 \mathrm{e}^{-05}$ & $5.45 \mathrm{e}^{-11}$ \\
\hline $\mathrm{G}_{\mathrm{B}}$ & \multicolumn{8}{|c|}{ Participation factors of generator $\mathrm{G}_{\mathrm{B}}$} \\
\hline $\mathrm{T}_{12 \mathrm{~B}}$ & $3.20 \mathrm{e}^{-06}$ & $1.05 \mathrm{e}^{-06}$ & $1.48 \mathrm{e}^{-04}$ & $8.25 \mathrm{e}^{-03}$ & $1.91 \mathrm{e}^{-12}$ & $1.12 \mathrm{e}^{-01}$ & $3.85 \mathrm{e}^{-01}$ & $1.59 \mathrm{e}^{-05}$ \\
\hline $\mathrm{T}_{23 \mathrm{~B}}$ & $4.65 \mathrm{e}^{-05}$ & $9.14 \mathrm{e}^{-06}$ & $3.85 \mathrm{e}^{-04}$ & $2.16 \mathrm{e}^{-03}$ & $9.59 \mathrm{e}^{-11}$ & $3.85 \mathrm{e}^{-01}$ & $1.11 \mathrm{e}^{-01}$ & $1.30 \mathrm{e}^{-03}$ \\
\hline $\mathrm{T}_{34 \mathrm{~B}}$ & $6.12 \mathrm{e}^{-10}$ & $3.96 \mathrm{e}^{-09}$ & $1.20 \mathrm{e}^{-06}$ & $7.47 \mathrm{e}^{-06}$ & $1.47 \mathrm{e}^{-10}$ & $8.98 \mathrm{e}^{-04}$ & $4.25 \mathrm{e}^{-04}$ & $4.99 \mathrm{e}^{-01}$ \\
\hline $\mathrm{S}_{1 \mathrm{~B}}$ & $1.05 \mathrm{e}^{-05}$ & $2.11 \mathrm{e}^{-06}$ & $1.86 \mathrm{e}^{-04}$ & $6.47 \mathrm{e}^{-03}$ & $6.94 \mathrm{e}^{-13}$ & $1.51 \mathrm{e}^{-01}$ & $3.01 \mathrm{e}^{-01}$ & $4.97 \mathrm{e}^{-06}$ \\
\hline $\mathrm{S}_{2 \mathrm{~B}}$ & $3.17 \mathrm{e}^{-05}$ & $3.29 \mathrm{e}^{-06}$ & $4.69 \mathrm{e}^{-05}$ & $3.06 \mathrm{e}^{-03}$ & $1.33 \mathrm{e}^{-11}$ & $6.11 \mathrm{e}^{-02}$ & $1.48 \mathrm{e}^{-01}$ & $1.49 \mathrm{e}^{-04}$ \\
\hline $\mathrm{S}_{3 \mathrm{~B}}$ & $6.63 \mathrm{e}^{-07}$ & $2.26 \mathrm{e}^{-06}$ & $3.39 \mathrm{e}^{-04}$ & $8.40 \mathrm{e}^{-04}$ & $3.65 \mathrm{e}^{-10}$ & $2.84 \mathrm{e}^{-01}$ & $4.73 \mathrm{e}^{-02}$ & $5.99 \mathrm{e}^{-03}$ \\
\hline $\mathrm{S}_{4 \mathrm{~B}}$ & $6.37 \mathrm{e}^{-09}$ & $2.51 \mathrm{e}^{-08}$ & $4.76 \mathrm{e}^{-06}$ & $1.85 \mathrm{e}^{-05}$ & $1.69 \mathrm{e}^{-10}$ & $3.82 \mathrm{e}^{-03}$ & $1.05 \mathrm{e}^{-03}$ & $4.94 \mathrm{e}^{-01}$ \\
\hline $\begin{array}{l}\text { Identified } \\
\text { mode }\end{array}$ & $\mathrm{TM}_{1 \mathrm{G}_{\mathrm{A}}}$ & $\mathrm{TM}_{2 \mathrm{G}_{\mathrm{A}}}$ & $\mathrm{TM}_{3 \mathrm{G}_{\mathrm{A}}}$ & $\mathrm{TM}_{4 \mathrm{G}_{\mathrm{A}}}$ & $\mathrm{TM}_{5 \mathrm{GA}_{\mathrm{A}}}$ & $\mathrm{TM}_{1 \mathrm{~GB}}$ & $\mathrm{TM}_{2 \mathrm{~GB}}$ & $\mathrm{TM}_{3 \mathrm{~GB}}$ \\
\hline
\end{tabular}
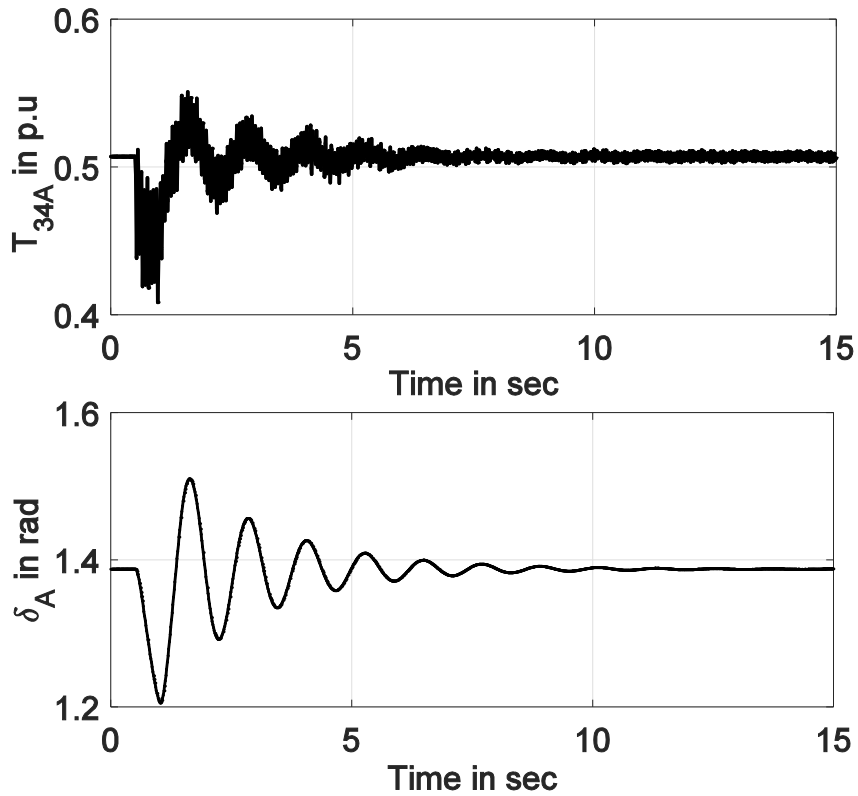

Figure 8: Sectional torque and rotor angle of generator $\mathrm{G}_{\mathrm{A}}$ with proposed KF based SSDC for the compensation $\mathrm{Xc}=0.35 \mathrm{p} . \mathrm{u}$ activated at $\mathrm{t}=4 \mathrm{sec}$.
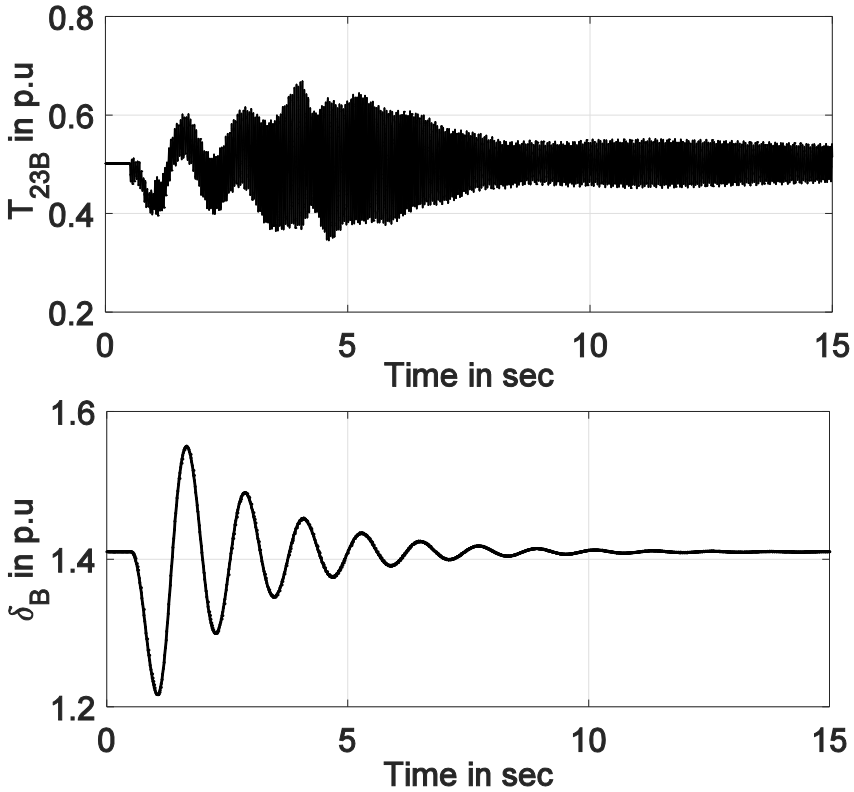

Figure 9: Sectional torque and rotor angle of generator $G_{B}$ with proposed KF based SSDC for the compensation Xc $=0.35 \mathrm{p} . \mathrm{u}$ activated at $\mathrm{t}=4 \mathrm{sec}$. 


\subsection{Discussion}

We proposed a multimodal SSDC using KF for multi-machine system to enrich all critical torsional mode frequencies. From the results, it is clear that the highest negative damping is noticeably decreased with proposed KF based SSDC in the entire range of critical torsional mode frequencies. The proposed KF based SSDC effectively mitigates multimodal SSR

\section{CONCLUSION}

We proposed a multimodal SSDC using KF for multi-machine system. The SSR analysis is carried out on the modified IEEE FBM with the inclusion of four-mass turbine-generator and SSSC. The parameters of KF based SSDC are selected to enhance the damping of all critical torsional mode frequencies and to mitigate the multimodal SSR. The SSR analysis is performed through damping torque, eigenvalue and transient simulation methods to validate the proposed KF based SSDC. The results demonstrated that the peak negative damping viewed at both generators is substantially reduced with proposed KF based SSDC and effectively mitigates SSR.

\section{REFERENCES}

1. K. R. Padiyar. Analysis of subsynchronous resonance in power systems, Boston: Kluwer Academic Publishers, 1999. https://doi.org/10.1007/978-1-4615-5633-6

2. K. R. Padiyar and Nagesh Prabhu. A Comparative study of SSR Characteristics of TCSC and SSSC, in Proc. PSCC conf., Aug. 2005.

3. S. Venkateswarlu, M. Janaki, R. Thirumalaivasan and Nagesh Prabhu. A review on damping of torsional interactions using VSC based FACTS and subsynchronous damping controller, Annual Reviews in Control, vol. 46, pp. 251-264, Aug. 2018.

4. S. Venkateswarlu, S. Velpula, M. Janaki and R. Thirumalaivasan. Analysis of SSR with SSSC using FPA based Voltage Controller, in Proc. of Innovations in Power and Advanced Computing Technologies (i-PACT), vol. 1, pp. 1-6, Mar. 2019.

5. D. Rai, S. O. Faried, G. Ramakrishna and Abdel-Aty (Aty) Edris. An SSSC-based hybrid series compensation scheme capable of damping subsynchronous resonance, IEEE Trans. on Power Delivery, vol. 27, no. 2, pp. 531-540, Apr. 2012. https://doi.org/10.1109/TPWRD.2011.2175253

6. Amir Ghorbani, Babak Mozaffari and A. M. Ranjbar. Application of subsynchronous damping controller (SSDC) to STATCOM, International Journal of Electrical Power and Energy Systems, vol. 43, no. 1, pp. 418-426, Dec. 2012.

7. Massimo Bongiorno, Jan Svensson and Lennart Angquist. Online estimation of subsynchronous voltage components in power systems, IEEE Trans. on Power Delivery, vol. 23, no. 1, pp. 410-418, Jan. 2008.

8. M. Bongiorno, J. Svensson and L. Angquist. On control of static synchronous series compensator for SSR mitigation, IEEE Trans. on Power Electronics, vol. 23, no. 2, pp. 735-743, Mar. 2008. https://doi.org/10.1109/TPEL.2007.915178

9. M. Bongiorno, L. Angquist and J. Svensson. A novel control strategy for subsynchronous resonance mitigation using SSSC, IEEE Trans. on Power Delivery, vol. 23, no. 2, pp. 1033-1041, Apr. 2008.

10. R. Thirumalaivasan, M. Janaki and Nagesh Prabhu. Damping of SSR using subsynchronous current suppressor with SSSC, IEEE Trans. on Power Syst., vol. 28, no. 1, pp. 64-74, Feb. 2013.

11. R. Thirumalaivasan, M. Janaki and Yunjian Xu. Kalman filter based detection and mitigation of subsynchronous resonance with SSSC, IEEE Trans. on Power Syst., vol. 32, no. 2, pp. 1400-1409, Mar. 2017.

12. Xiaorong Xie, Yuanqu Zhang and Zhipeng Li. Damping multimodal subsynchronous resonance using a generator terminal subsynchronous damping controller, Electric Power Systems Research. vol. 99, pp. 1-8, Jun. 2013.

13. Xiaorong Xie, Liang Wang, Xijiu Guo, Qirong Jiang, Quan Liu and Yonglin Zhao. Development and field experiments of a generator terminal subsynchronous damper, IEEE Trans. on Power Electronics, vol. 29, no. 4, pp. 1693-1701, Apr. 2014. https://doi.org/10.1109/TPEL.2013.2267550

14. Xiaoliang Dong, Xiaorong Xie, Yingduo Han, Liang Wang and Dawei Sun. Coordinated parameters design of SEDC and GTSDC for SSR mitigation, in Proc. PES General Meeting Conference and Exposition, pp. 1-5, Jul. 2014.

15. Xiaorong Xie, Liang Wang and Yingduo Han. Combined application of SEDC and GTSDC for SSR mitigation and its field tests, IEEE Trans. on Power Syst., vol. 31, no. 1, pp. 769-776, Jan. 2016.

16. Liang Wang, Xiaorong Xie, Qirong Jiang and Hemanshu R. Pota. Mitigation of multimodal subsynchronous resonance via controlled injection of supersynchronous and subsynchronous currents, IEEE Trans. on Power Syst., vol. 29, no. 3, pp. 1335-3101, May. 2014. https://doi.org/10.1109/TPWRS.2013.2292597

17. Zahid Ali Wani, Nawaz Shafi, Rayees Ahmad Thokar and Gagandeep Yadav. Investigation using conventional and automatic differential approach on power flow models of TCSC, International Journal of Emerging Technologies in Engineering Research, vol. 6, no. 11, pp. 59-64, Nov. 2018.

18. S. Venkateswarlu and M. Janaki. Software-in-the-loop testing of SSSC with type-1 controller connected to SMIB, International Journal on Emerging Technologies, vol. 11, no. 3, pp. 59-64, Mar. 2020. 